\title{
Educación inclusiva en contexto: reflexiones sobre la implementación del Decreto 1421 del 2017
}

\author{
Inclusive education in context: Reflections upon the implementation of the \\ decree 1421 of 2017
}

Educação inclusiva em contexto: reflexões sobre a implementação do Decreto 1421 de 2017

Recepción: 23/06/2019

Evaluación: 02/03/2020

Aceptación: 01/04/2020

Artículo de Investigación

https://doi.org/10.19053/01227238.9823

Alexandra Díaz-Piñeres
https://orcid.org/0000-0003-0314-0765
Universidad de Pamplona, Colombia
Carolina Bravo-Rueda ${ }^{3}$
https://orcid.org/0000-0003-0417-9725
Psinergia, Colombia
Gloria Esperanza Sierra Delgado
https://orcid.org/0000-0003-2395-4344
Colegio Vicente Azuero, Colombia

RESUMEN

Objetivo: analizar los retos y oportunidades que enfrentan las instituciones en la implementación del Decreto 1421 de 2017 del Ministerio de Educación de Colombia, mediante acompañamiento técnico-pedagógico, el cual se desarrolló en un colegio público rural de Santander. El problema aborda la exclusión escolar desde las dificultades para implementar la normativa que orienta la atención de personas con discapacidad en el marco de la educación inclusiva. Método: investigación cualitativa, de alcance descriptivo y experimental, de tipo investigación-acción práctica. Estrategias: realizando el análisis del discurso con base en las dimensiones para el mejoramiento institucional de políticas, prácticas y cultura. Originalidad: el proceso permitió la identificación de factores que facilitan y dificultan la

1 Resultado de la investigación llevada a cabo en el contexto de la tesis de maestría en Educación con la Universidad Autónoma de Bucaramanga, bajo la dirección de licenciada Gloria Esperanza Sierra Delgado. Artículo resultado del proyecto de investigación en educación inclusiva.

2 Psicóloga, especialista en gerencia de proyectos, docente de prácticas del Programa de Psicología en la Universidad de Pamplona. Correo electrónico: adiaz534@unab.edu.co, alexandra.diaz2@unipamplona.edu.co, orcid.org/ 0000-0003-0314-0765

3 Psicóloga asociada a Psinergia Servicios Profesionales, asesora pedagógica en educación inclusiva. Correo electrónico: carolina. bravorueda@hotmail.com orcid.org/0000-0003-0417-9725

4 Magíster en Educación, docente del Colegio Vicente Azuero. Correo electrónico: gsierra656@unab.edu.co. orcid.org/ 0000-00032395-4344 
provisión de un servicio de calidad para todos, minimizando el problema de la exclusión y facilitando la construcción y actualización de procesos institucionales. Conclusiones: los resultados permitieron identificar los retos y oportunidades que se presentan en el camino de la educación inclusiva, los procesos de acompañamiento sistematizados y adaptados al contexto, desarrollados con tiempos suficientes y liderados por los miembros de la comunidad impactan directamente en el sistema educativo, generando dinámicas y reformas que favorecen el acceso, la permanencia y la calidad educativa de todos los estudiantes.

Palabras clave: Decreto 1421; educación; aprendizaje; institución educativa.

\section{ABSTRACT}

Taking into account the importance of the processes of inclusive education in the Colombian context and how the incorporation of new practices preceded by the diffusion of the norm, can generate conflicts within the educational community, the objective of this work was to analyze the challenges and opportunities that the institutions face in the implementation of Decree 1421 of 2017 of the Ministry of Education of Colombia, it was developed in a rural public school in the department of Santander through a technical-pedagogical support. The problem addresses the school exclusion regarding the difficulties of implementing the norm that guide the care of people with disabilities within the framework of inclusive education. The research was carried out under the qualitative methodological approach, descriptive and experimental, of a research-practical action type. There was applied the discourse analysis based on the dimensions for the institutional improvement of policies, practices, and culture. The process allowed the identification of factors that can facilitate or can hinder the provision of a quality of service for all, minimizing the problem of exclusion and making easier the construction of institutional processes in an updated way. This research concludes that to face the challenges and opportunities that arise on the path of inclusive education, the systematized accompanying processes and adapted to the context, developed during enough period of time and lead for the members of communities impact directly in the educational system, developing new dynamics and reforms to be part of, the stay and quality of all students.

Key words: Decree 1421; education; learning; educational institution.

\section{RESUMO}

Considerando a importância dos processos da educação inclusiva no contex to colombiano e como a implementação de novas práticas precedidas pela difusão da norma podem gerar tensões dentro da comunidade educacional, o objetivo do presente trabalho consistiu em analisar os desafios e possibilidades que enfrentam as instituições na implementação do Decreto 1421 de 2017 do Ministério da Educação da Colômbia, mediante acompanhamento técnico-pedagógico, o qual se desenvolveu em um colégio público rural do estado de Santander. O problema aborda a exclusão escolar desde as dificuldades para imple- mentar a normativa que orienta a atenção de pessoas com deficiência no marco da educação inclusiva. A pesquisa se desenvolveu sob o enfoque metodológico qualitativo, de forma descritiva e experimental, de tipo pesquisa-ação prática, realizando a análise do discurso com base nas dimensões para aprimoramento institucional de políticas, práticas e cultura. O processo permitiu a identificação de fatores que facilitam e dificultam a prestação de um serviço de qualidade para todos, minimizando o problema da exclusão e facilitando a construção e atualização de processos institucionais. Essa pesquisa conclui que para afrontar 
os desafios e possibilidades que se apresentam no caminho para a construção de uma educação inclusiva, os processos de acompanhamentos sistematizados e adaptados ao contexto, desenvolvidos com tempos suficientes e liderados pelos membros das comunidades, impactam diretamente no sistema educativo, gerando novas dinâmicas e reformas que favorecem $o$ acesso, a permanência e a qualidade educativa de todos os estudantes.

Palavras-chave: Decreto 1421; educação; aprendizagem; instituição educacional.

\section{INTRODUCCIÓN}

Para hablar de la educación inclusiva en el contexto colombiano debemos partir del problema que se pretendió abordar con la investigación, un problema enmarcado por la exclusión. La UNESCO, y todas las organizaciones que la apoyan, han identificado la educación como elemento clave para el desarrollo humano y de las sociedades 5 , pero existen cifras preocupantes a escala mundial que dejan ver cómo la población infantil no cuenta con el pleno goce del derecho a la educación. En la literatura nacional se encuentra evidencia que apunta a que la educación inclusiva ha sido investigada enfáticamente desde la perspectiva en la que es necesaria para la correcta inserción educativa de personas en condición de discapacidad ${ }^{678910}$, como si se ignorara que el principio básico de este concepto hace referencia a las adaptaciones necesarias para la educación de todos los estudiantes y no solo de aquellos que quepan en la categoría de especiales o discapacitados ${ }^{11}$.

Por otro lado, la literatura internacional indica diversas formas de procurar calidad en tal escolarización por medio de la implementación de una educación inclusiva que desarrolle adaptaciones curriculares ${ }^{12}{ }^{13}$, las cuales no buscan ser dirigidas a colectivos específicos sino a toda la comunidad estudiantil. Según el informe global "Las múltiples caras de la exclusión", publicado por Save the Children en el 2018, más de la mitad de la población infantil en el mundo, es decir, mil doscientos millones de niños y niñas, están expuestos a situaciones de

5 Organización de las Naciones Unidas para la Educación, la Ciencia y la Cultura (UNESCO), "Garantizar el acceso a la educación para todos", (2005): 13-22.

6 Leidy Vanessa Quintanilla Rubio, “Un camino hacia la educación inclusiva: análisis de normatividad, definiciones y retos futuros" (tesis maestría en Universidad Nacional de Colombia, 2014), 107.

7 Elba Rosa Figueredo Vila, Ricardo Campuzano Peña, Clara María Rodríguez Vázquez; "Estrategia compensatoria dirigida a la estimulación del pensamiento en escolares con discapacidad intelectual leve", Revista Dilemas Contemporáneos: Educación, Política $y$ Valores $n .^{\circ} 2$ (2019): 1-21.

8 Idurre Lazcano Quintana y Aurora Madariaga Ortuzar, “La experiencia de ocio en las personas jóvenes con discapacidad”, Pedagogía Social. Revista interuniversitaria n. $^{\circ} 31$ (2018): 101-121. DOI: 10.7179/PSRI_2018.31.09

9 M. Médicis; Roicer Flórez Bolívar, "Proceso de Integración Educativa: Accesibilidad, promoción y permanencia de personas sordas en el sistema educativo, en el nivel básica primaria en el sector público y privado en Bogotá. D.C.” (tesis maestría en, Universidad Nacional de Colombia, 2007): 108.

10 María Fernanda Romero Hernández y Sara Urrego González, "Inclusión de personas con discapacidad sensorial (ciegos y sordos) en los programas de formación musical universitaria en la ciudad de Bogotá, D. C., Uni-pluri/versidad vol. 16, n. 2 (2016): 27-40.

11 Gerardo Echeita Sarrionandía, "Competencias esenciales en la formación inicial de un profesorado inclusivo. Un proyecto de la Agencia Europea para el Desarrollo de las Necesidades Educativas Especiales”, Tendencias Pedagógicas vol. 19 (2012): 8-24.

12 UNESCO, "Garantizar el acceso a la educación".

13 Echeita, "Competencias esenciales". 
violencia, pobreza y discriminación, y es en América Latina y el Caribe donde se registran las cifras más elevadas, siendo Colombia uno de los cinco países que enfrentan la situación es más grave ${ }^{14}$. De acuerdo con la UNESCO, si no se adoptan medidas inmediatamente será imposible cumplir con la promesa, expresada por todos los Estados en el marco de la Agenda 2030, de asegurar el derecho de los niños y las niñas a sobrevivir, aprender y estar protegidos ${ }^{15}$. Solo en Colombia, para el 2005, existían más de dos millones y medio de personas en condición de discapacidad, de las cuales el $42 \%$ solo alcanzó a culminar su primaria, mientras el $31 \%$ no tuvo acceso a la educación ${ }^{16}$. Para el 2019, la cifra de discapacitados aumentó a tres millones cuatrocientas setenta mil personas, pero la discapacidad no es la única situación de vulnerabilidad social que puede generar exclusión; también hay cifras preocupantes de desplazamiento forzado y migrantes, por mencionar únicamente aquellas situaciones cuyas cifras se encuentran documentadas a la fecha ${ }^{17}$. ¿Una solución? La articulación efectiva de la educación inclusiva con el quehacer de las instituciones educativas, entendiendo esta como una educación adaptable a las necesidades de todos los estudiantes, pero para que eso ocurra en nuestro país, ¿qué hace falta?

La evidencia empírica comprueba que la concepción limitada y dificultades inherentes a los procesos de inclusión educativa no solo están plasmadas en el papel $^{18}$, sino que también se ven reflejadas en términos prácticos dentro de las aulas $^{19}$. En la actualidad, el proceso se encuentra en la intersección entre la integración escolar y la inclusión escolar, por lo que dicho proceso suele entenderse como el simple acto de tener niños y niñas con necesidades educativas, es decir, que presenten dificultades respecto a sus demás compañeros para acceder a los conocimientos que deben dominar de acuerdo con su edad o grado escolar, razón por la cual requiere apoyos especializados; sin embargo, los estudiantes a los que se les atribuyen tales necesidades educativas son habitualmente categorizados dentro de un espectro limitado de discapacidades físicas, sensoriales, mentales y $\operatorname{cognitivas}^{20}$, considerándose erróneamente que aquellos pertenecientes a dicho espectro son los únicos que necesitan tales apoyos.

14 Save the Children, "Las múltiples caras de la exclusión" (Save the Children, 2018), https://www.savethechildren.org.co/articulo/ informe-global-las-m\%C3\%BAltiples-caras-de-la-exclusi\%C3\%B3n (8 de abril, 2020).

15 Comisión Económica para América Latina y el Caribe (CEPAL), La Agenda 2030 y los Objetivos del Desarrollo Sostenible. Una oportunidad para América y el Caribe (Santiago de Chile: CEPAL, 2019), https://repositorio.cepal.org/bitstream/handle/11362/40155/24/ S1801141_es.pdf (8 de abril, 2020).

16 Departamento Administrativo Nacional de Estadística (DANE), "Informe Especial. Censo General 2005. Colombia - Educación” (Bogotá: DANE, 2005), https://www.dane.gov.co/files/censos/boletines/bol_educacion.pdf (8 de abril, 2020).

17 Departamento Administrativo Nacional de Estadística (DANE), "Resultados Censo Nacional de Población y Vivienda 2018" (Bogotá: DANE, 2018), https://www.dane.gov.co/files/censo2018/informacion-tecnica/cnpv-2018-presentacion-3ra-entrega.pdf (9 de abril, 2020).

18 Alexander Javier Montes Miranda y Audin Aloiso Gamboa Suárez, "Miradas sobre la calidad de la educación básica en Iberoamérica: Visiones de España y Colombia”, Revista Historia de la Educación Latinoamericana, vol. 20, n. 31 (2018): 229-244. https://doi. org/10.19053/01227238.8721

19 Echeita, “Competencias esenciales".

20 Isabel Margarita López y Gloria Elena Valenzuela, "Niños y adolescentes con necesidades educativas especiales", Revista Médica Clínica Las Condes vol. 26, n. ${ }^{\circ}$ 1. (2015): 42-51. https://doi.org/10.1016/j.rmclc.2015.02.004 
Es por lo anterior que cobra valor investigativo el analizar las orientaciones técnicas y administrativas a seguir en los documentos institucionales emitidos por el Estado colombiano en busca de vacíos o dificultades para su comprensión e implementación, ya que dichos obstáculos pudieran ser idealmente amortiguados con un acompañamiento técnico y pedagógico dirigido a lograr una sinergia funcional entre la normativa colombiana y las prácticas educativas institucionales, con miras a avanzar hacia un sistema más inclusivo.

La población estudiantil discapacitada es uno de los grupos poblacionales con mayores factores de riesgo de exclusión ${ }^{21}$, y a su vez, al problema se suma una dificultad social para reconocer la discapacidad como una condición humana diversa que requiere respeto y apoyo ${ }^{22}$. Esta situación de riesgo no solo se limita a la población discapacitada; el desconocimiento de otras realidades individuales y sus respectivas necesidades educativas agravan el problema, aumentando la cantidad de estudiantes que requieren iniciar procesos inclusivos en contextos en donde no se saben reconocer o direccionar los mismos, puesto que las inequidades sociales que las personas con discapacidades encuentran son muy similares a aquellas encontradas, por ejemplo, en casos de sujetos pertenecientes a minorías sociales 232425262728293031 .

En el 2012, el MEN consideró que si bien las políticas locales pretendían ofrecer un escenario participativo y organizativo más favorable, además de estar enfocadas únicamente en situaciones de discapacidad, no ofrecían la certeza de ser de fácil seguimiento puesto que en ese momento los procesos inclusivos obligatorios aplicados a la educación se encontraban apenas en fase de pilotaje. Visto lo anterior, el implementar la educación inclusiva no debía suponer un proceso homogéneo de aplicación, con lo cual la manera de ejecutarse tendría

21 "Contrato 00000506 del 2016 de apoyo pedagógico a la permanencia e inclusión educativa con calidad para estudiantes con necesidades especiales educativas de establecimientos educativos de municipios no certificados" (Bucaramanga, 2016), Informe publicado en Archivo de Contratos de la Secretaría de Educación Departamental (SED). Gobernación de Santander.

22 Sophie Mitra, “The Capability Approach and Disability”, Journal of Disability Policy Studies vol. 16, n. ${ }^{\circ} 4$ (2006): 236-247. https://doi. org/10.1177/10442073060160040501

23 CEPAL, La Agenda 2030.

24 López y Valenzuela, "Niños y adolescentes".

25 Mitra, "The Capability Approach".

26 Piedad Cabrera, “QQué debe saber y saber hacer un profesor de estudiantes con talento académico? Una propuesta de estándares de formación inicial en educación de talentos", Estudios pedagógicos vol. 37, n. ${ }^{\circ} 2$ (2011): 43-59. http://dx.doi.org/10.4067/S071807052011000200002

27 José Devís Devís, Jorge Fuentes Miguel y Andrew Sparkes, “¿Qué permanece oculto del currículum oculto? Las identidades de género y de la sexualidad en la educación física”, Revista Iberoamericana de Educación n. ${ }^{\circ} 39$ (2005): 73-90.

28 Leidys Tatiana Hurtado Lozano y María Alejandra Agudelo Martínez, "Inclusión educativa de las personas con discapacidad en Colombia”, Revista CES Movimiento y Salud vol. 2, n. ${ }^{\circ} 1$ (2014): 45-55.

29 Ana María Ibáñez y Carlos Eduardo Vélez, Instrumentos de atención de la población desplazada en Colombia: Una distribución desigual de las responsabilidades municipales (Bogotá: Centro de Estudios sobre Desarrollo Económico, Universidad de los Andes, Facultad de Economía, 2003), 37.

30 Christine O’Hanlon, Inclusión educacional como investigación-acción. Un discurso interpretativo (Bogotá: Editorial Magisterio, 2009), 187.

31 Programa Mundial de Alimentos (PMA), "Estudio de caso de las necesidades alimentarias de la población desplazada de Colombia" (Bogotá: PMA, 2001) https://reliefweb.int/report/colombia/estudio-de-caso-de-las-necesidades-alimentarias-de-la-poblaci\%C3\%B3n-desplazada-de (9 de abril, 2020). 
que ser necesariamente diferente en cada institución educativa, siendo que cada escuela debería emprender su propia ruta para avanzar hacia la inclusión ${ }^{32}$.

La evolución de la educación inclusiva estuvo alimentada, a través del tiempo, por perspectivas teóricas sólidas que le dieron continuidad y soportaron su quehacer en diferentes momentos. Las disciplinas científicas médicas y psicológicas, tanto como las filosóficas y pedagógicas, matizaron dicha evolución a través de los aportes teóricos y prácticos de sus representantes. Para el caso específico de discapacidad, anterior a estos teóricos se formuló el primer modelo de atención, el modelo de caridad, en donde las personas discapacitadas eran consideradas, como su nombre lo dice, objeto de la caridad, muchas veces dejadas a su suerte. Los primeros académicos consultados que teorizaron sobre la educación fueron los filósofos Rousseau y Kant, que compartieron la idea de que la educación permite el progreso social al perfeccionar al hombre. Más adelante, con Freud ocurre la transición del modelo de caridad al modelo médico, a mediados del siglo XIX: este "considera la discapacidad como un problema del individuo que es directamente causado por una enfermedad, una herida o alguna otra condición de salud y que requiere de cuidado médico en la forma de tratamiento o rehabilitación" ${ }^{\prime 33}$. Si bien este modelo propone una perspectiva de rehabilitación, continúa caracterizando al individuo a través de aquello que lo limita.

Más adelante, Durkheim retoma las ideas de educación moral de Kant y Dewey complementa su perspectiva generando las primeras nociones de igualdad social, dando paso a autores como Decroly, Montessori, Freinet y Vigotsky, quienes representarán las ideas del modelo social, en donde la discapacidad se entiende como un concepto asociado al entorno social, el cual supone en muchos casos un factor limitante para el desarrollo social del sujeto.

Luego vendrán autores como Ausubel, Bruner y Piaget, quienes comprenden que la socialización tiene un factor fundamental en la maduración psíquica del sujeto. Después, Bandura, Gardner, Bordieu y Freire complementarán esta postura, desarrollando ideas como las de los entornos de aprendizaje, la regulación social y la educación bancaria, gestando una crítica a la educación que dará pie para que inicie el modelo de atención social de derechos que busca, antes que nada, responder a las necesidades y expectativas de la persona.

Los autores contemporáneos de la educación inclusiva son Gerardo Echeita, Gordon Porter y David Towell, quienes reafirman la educación como un derecho, en donde se requiere de trabajo colaborativo para fortalecer los procesos de enseñanza-aprendizaje. Estos autores defienden la educación inclusiva como un derecho de todos los seres humanos. Echeita define la educación inclusiva como una ambición poliédrica que posee múltiples significados, razón por la cual considera que su alcance resulta difícil de clarificar, siendo esta al mismo tiempo

32 Ministerio de Educación Nacional (MEN), "Orientaciones Generales para la atención educativa de las poblaciones con discapacidad, en el marco del derecho a la educación” (Bogotá: MEN, 2012) http://www.insor.gov.co/home/wp-content/uploads/filebase/ orientaciones_poblacion_discapacidad_2012.pdf (9 de abril, 2020). 
un derecho humano, un medio para alcanzar la plena realización del mismo, un principio que valora el bienestar de todos los estudiantes y un proceso que requiere de implicación y compromiso continuos por parte de toda la comunidad educativa ${ }^{34} 35$.

Para Echeita, la educación inclusiva debe considerar una serie de dimensiones de modo que resulte funcional dentro de los sistemas educacionales: esta debe procurar la presencia en espacios educativos comunes, escolares y extraescolares, de todos los estudiantes sin excepción, su participación activa en el aprendizaje traducida en el buen rendimiento académico y la percepción de bienestar socioemocional, y la comprensión sistémica de toda la comunidad, para que las políticas a implementar lleguen a todos los subsistemas a través de su constante práctica, lo cual terminará por generar transformación de la cultura escolar ${ }^{36}{ }^{37}$.

Gordon Porter es otro de los autores contemporáneos que complementan la visión actual de lo que es la educación inclusiva. Porter asegura que son los maestros quienes diseñan las estrategias para los estudiantes, apoyados por un grupo de profesionales idóneos, porque se debe tener presente que la finalidad del equipo de apoyo es enseñar a los profesores, no a los estudiantes, sin generar dependencias posteriores ${ }^{3839}$.

Gordon Porter desde su experiencia en Canadá, y David Towell como promotor de la igualdad ciudadana de las personas con discapacidad en Inglaterra, han coincidido en los últimos años sobre los puntos clave en la transformación de las culturas escolares. Estos autores confluyen en la perspectiva que la educación inclusiva para todos requiere un cambio transformacional en los sistemas de educación pública, para que la inclusión se convierta en una característica intrínseca de la política, la cultura y la práctica; asimismo coinciden en lo relacionado con el trabajo en las aulas y la escuela, rescatando las ideas de trabajo colaborativo que mencionan autores anteriores ${ }^{40}$.

Para ellos también se requiere de tiempo suficiente para realizar las incorporaciones dentro del aula, así como para que todo el sistema funcione en concordancia con las reformas efectuadas; además es necesaria la incorporación y articulación de todos los actores del proceso educativo, por lo que familias, estudiantes, docentes, rectores, responsables de las políticas públicas, líderes de las comunidades y cualquier otro miembro de la sociedad en la que la institución se encuentre inmersa, deben estar involucrados y comprometidos, tanto con la

34 Gerardo Echeita Sarrionandia, "Educación inclusiva: de los sueños a la práctica del aula”, Cuaderno de Educación n. ${ }^{\circ} 75$ (2016): 1-9

35 Cecilia Simón Rueda y Gerardo Echeita Sarrionandia, “Educación inclusiva: ¿de qué estamos hablando?”, HerひMus, Heritage \& Museography n. ${ }^{\circ} 17$ (2016): 25-37.

36 Echeita, "Educación inclusiva: de los sueños".

37 Simón y Echeita, "Educación inclusiva: ¿de qué?

38 Juan Bustamante y Carolina Mejía, "Acciones y herramientas de software para implementar entornos de inclusión educativa en Colombia”, Teknos vol. 17, n. ${ }^{\circ} 2$ (2017): 38-45.

39 Gordon Porter y David Towell, Promoviendo la educación inclusiva. Claves para el cambio transformacional en los sistemas de educación (New Brunswick, Canadá: Inclusive Education Canada / Centre for Inclusive Futures, 2017), https://www.plenainclusion. org/sites/default/files/promoviendo_la_educacion_inclusiva.pdf (9 de abril, 2020).

40 Ibíd. 
filosofía de la educación inclusiva como con los cambios que se introduzcan al sistema $^{41}$.

Porter y Towell afirman que la inclusión no es solo la incorporación de las personas con discapacidad, pues hay otras poblaciones que afrontan la exclusión educativa por otras razones, como la necesidad de trabajar para apoyar la economía familiar, la pertenencia a pandillas, el desplazamiento por los conflictos, la discriminación étnica, entre otras, para lo que se requiere de participación y adaptación social gradual. Se debe empoderar a la comunidad, realizar reformas políticas y estructurales que den validez al proceso, fomentar el desarrollo profesional y contar con agencias facilitadoras que aseguren el cambio ${ }^{42} 43$.

Para las instituciones educativas no solo es indispensable contar con planteamientos claros en cuanto al trabajo metodológico y administrativo que deben desarrollar, también requieren para la permanencia de los estudiantes de sistematización de procesos y herramientas útiles para desarrollar un trabajo colaborativo eficaz entre familia y docentes ${ }^{44}$. Esta perspectiva no debe limitarse únicamente a la atención de estudiantes con discapacidades, sino que debe ser extrapolada a toda situación que represente dificultades funcionales o de acceso para un estudiante, ya que la participación integral de la familia y los docentes como entes pedagógicos principales en la educación es fundamental para la calidad educativa de todos los estudiantes ${ }^{45} 46$ y la importancia que el Estado colombiano le otorga a dicha conjunción se ve reflejada en la política nacional en el Decreto 1421 de $2017^{47}$.

Teniendo en cuenta que la educación necesita contribuir al desentrañamiento de la dinámica del conflicto, afianzando el compromiso político que apunta a superar las hondas desigualdades sociales de las que padece Colombia ${ }^{48}$, el trabajo educativo debe dar evidencias de procesos articulados con el contexto, que conecten de forma armónica las diferentes realidades sociales e institucionales con los procesos formales que son exigidos desde la normativa nacional.

La importancia definitiva de acompañar la implementación de los lineamientos establecidos en el Decreto 1421 del 2017 consiste en facilitar una

41 Ibíd.

42 Ibíd.

43 Heidy Tatiana Araque Sierra y David Towell, "Fomentar la educación inclusiva para forjar una sociedad inclusiva" (Bogotá: Centre for Inclusive Futures, 2011), https://www.javeriana.edu.co/documents/245769/2338340/FOMENTAR+EDUCAC+INCLUSIVA+FORJAR+SOCIEDAD+INCLUSIVA-DAVID-COTA.pdf/539338f5-7cc3-47b4-b814-57741a6413e2 (9 de abril, 2020).

44 Carlos Sancho-Álvarez, "Propuestas inclusivas de mejora desde un enfoque metodológico y organizacional", Revista Latinoamericana de educación inclusiva, vol. 7, n. ${ }^{\circ} 1$ (2013): 135-149.

45 Yolima Ivonne Beltrán Villamizar, Yexica Lizeth Martínez Fuentes y Omar Elías Torrado Duarte, "Creación de una comunidad de aprendizaje: una experiencia de educación inclusiva en Colombia”, Revista Encuentros, vol. 13, n. ${ }^{\circ} 2$ (2015): 57-72.

46 Eudés Desiderio Méndez Jiménez, "Estrategia de autoformación docente para mejorar el logro satisfactorio de aprendizajes en aula multigrado de la Institución Educativa n. ${ }^{\circ} 86627$-Shocosh" (tesis de segunda especialización en gestión escolar con liderazgo pedagógico, Universidad San Ignacio de Loyola, 2018), 37.

47 Ministerio de Educación Nacional (MEN), Decreto No 1421 de 2017: por el cual se reglamenta en el marco de la educación inclusiva la atención educativa a la población con discapacidad (Bogotá: Presidencia de la República de Colombia, 2017), http://es.presidencia. gov.co/normativa/normativa/DECRETO\%201421\%20DEL\%2029\%20DE\%20AGOSTO\%20DE\%202017.pdf (9 de abril, 2020).

48 Martha Cecilia Herrera, Alexis Pinilla Díaz y Raúl Infante Acevedo, “Conflicto educativo y cultura política en Colombia”, Nómadas, n. ${ }^{\circ} 15$ (2001): 40-49. 
articulación efectiva entre estos y el trabajo con aquellos estudiantes que requieren apoyos específicos por parte de la institución y sus docentes, teniendo en cuenta la novedad que representa el reto de adecuar el entorno para ello $\mathrm{o}^{49}$; por lo tanto, lo que se pretende con la presente investigación es comprender los retos y oportunidades que enfrentan las instituciones educativas en la implementación del Decreto 1421 de 2017 del MEN de Colombia en una institución rural santandereana, que permita proporcionar beneficios recíprocos para direccionar los procesos de la comunidad educativa, desarrollando acciones afirmativas en su beneficio y mitigando las barreras en la aplicación de la norma, creando en los docentes la percepción de capacidad institucional instalada, evidenciándose en capacidad para implementar efectivamente los lineamientos establecidos en el Decreto 1421 y de esa manera se ofrezcan mejores procesos institucionales para la atención de todos los estudiantes. Para lograr este propósito se plantearon como objetivos específicos el identificar las percepciones, las concepciones previas y los imaginarios de los miembros de un colegio público rural; describir la articulación de los procesos contenidos en el Decreto 1421 con el quehacer institucional; y describir los retos, oportunidades y el impacto alcanzados a partir del acompañamiento a los procesos educativos inclusivos.

\section{Desarrollo}

Se utilizó un diseño cualitativo, de corte descriptivo y experimental, de tipo investigación-acción, cuya unidad de análisis fue una comunidad educativa pública rural santandereana. Las fases de intervención fueron en total siete. Se inició con la identificación de la institución, para luego establecer el contacto inicial, que dio paso a la aplicación de las entrevistas iniciales, posteriores a las cuales se inició formalmente el proceso de acompañamiento, el cual estuvo dividido en tres momentos de ocurrencia intercalada: momentos de revisión documental (en los cuales se revisaron los formatos institucionales en aras de ser actualizados para que permitieran la sistematización de los procesos de inclusión educativa, buscando evitar añadir papelería adicional), momentos de capacitación (un total de tres, utilizados para ampliar los temas y conceptos pertinentes de acuerdo con el contexto y los presaberes de los colaboradores), y momentos de asesoría (de ocurrencia individual y según requerimiento de los docentes). Luego del acompañamiento vino la fase de aplicación final, en donde se recurrió al protocolo de entrevista final, justo antes de iniciar la fase de análisis de los datos obtenidos y el cierre del proceso con la institución. 
Gráfico 1. Fases de la investigación.

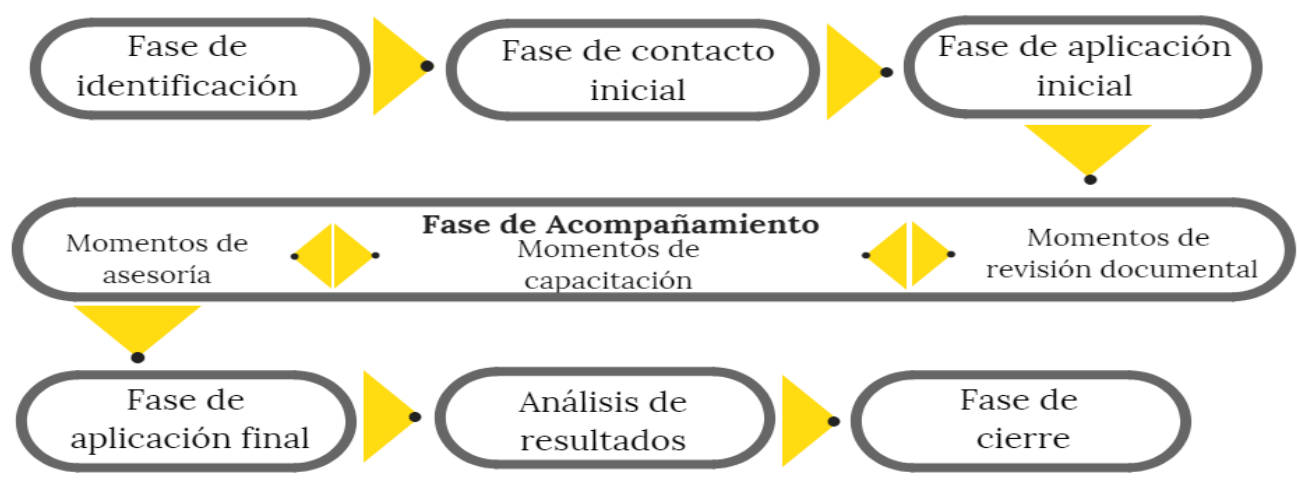

Fuente: elaboración propia.

La población participante en las entrevistas fueron once personas, de las cuales uno era directivo y diez eran docentes, con quienes se utilizó un muestreo por conveniencia. Los instrumentos utilizados fueron: los protocolos de entrevista inicial y final, el protocolo de revisión documental y prácticas institucionales, el material de capacitación y el software de análisis de datos cualitativos ATLAS.ti 8. Los métodos de recolección de información fueron la entrevista y la revisión documental.

Las categorías iniciales fueron tres: culturas, políticas y prácticas inclusivas definidas a partir de las dimensiones para el mejoramiento escolar de Booth y Ainscow $^{50}$ y del Decreto 1421 del 2017, y luego, a partir del análisis de resultados, se definieron cuatro categorías emergentes: información, entendida como todas aquellas formas que, refirieron los docentes, les permitían acceder a la información para proporcionar prácticas inclusivas; acciones, definidas como toda gestión y responsabilidades realizadas por el personal de la institución educativa; el estudiante, refiriéndose a todas las características propias del o los estudiantes con discapacidad que refirieron los docentes entrevistados; y barreras para la calidad educativa, entendidas como los obstáculos o limitantes generales que se presentan para poder ofrecer una mejor práctica de educación inclusiva. El análisis de los datos se realizó a través de triangulación metodológica.

El gráfico 2 ilustra la relación entre las tres categorías iniciales: cultura, políticas y prácticas; y las cuatro categorías emergentes, tanto en el discurso inicial como final: información, acciones, el estudiante y barreras para la calidad educativa, evidenciando que se encuentran interrelacionadas ya que la información contenida en las categorías emergentes expone eventos reflejados en el discurso que se relacionan con el desarrollo de prácticas, la producción de políticas y la creación de culturas dirigidas a la promoción de la educación inclusiva dentro de la institución, lo cual concuerda con los planteamientos de Booth y Ainscow ${ }^{51}$.

\footnotetext{
50 Tony Booth y Mel Ainscow, Index for Inclusion: developing learning and participation in schools (Bristol: Centre for Studies on Inclusive Education, 2002), 107.

51 Ibíd.
} 
Gráfico 2. Categorías de análisis iniciales y emergentes del discurso.

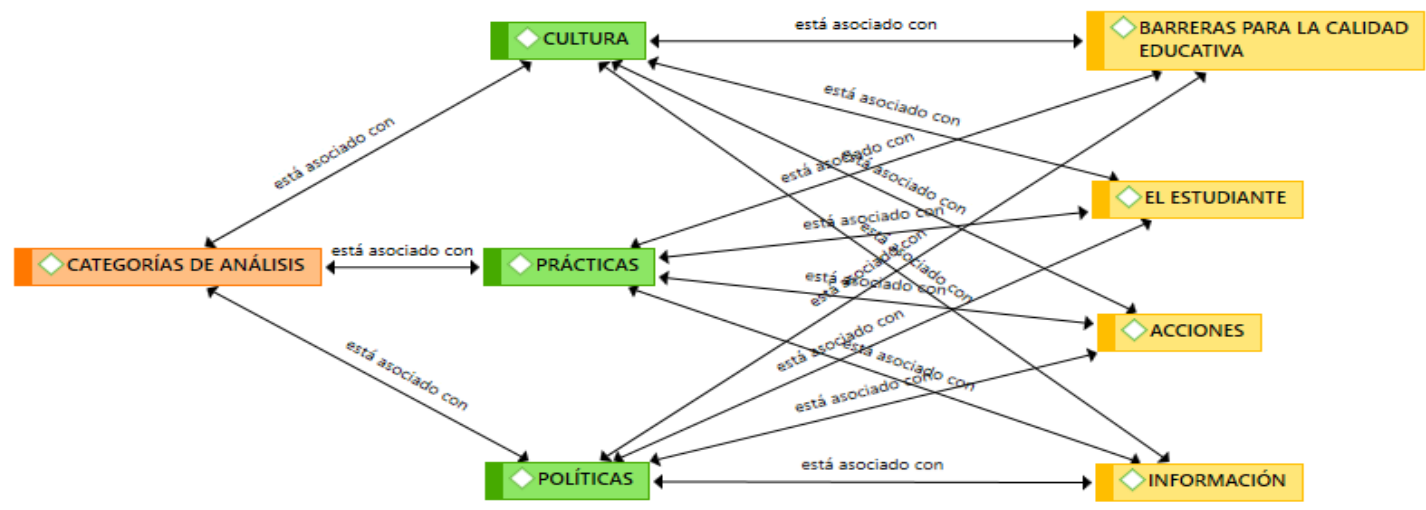

Fuente: elaboración propia basada en una imagen de ATLAS.ti 8.

El discurso de los participantes fue recopilado antes y después del proceso de acompañamiento, en aras de contrastar y comprender los efectos de promover procesos de trabajo colaborativo, fundamentados en la reflexión sobre la labor propia, tanto individual como institucionalmente, proceder sugerido por Pérez y $\mathrm{Nieto}^{52}$, quienes aseguran que, para darle solución a los problemas educativos, debe darse un proceso en bucle ininterrumpido de planificación, acción y reflexión, en donde el discurso involucre a los participantes al exponer y articular sus significaciones individuales en pro de la mejora en la calidad del servicio educativo.

Gráfico 3. Categoría emergente información junto con las subcategorías y categorías constituyentes con base en las cuales se desarrolló el análisis de las entrevistas iniciales.

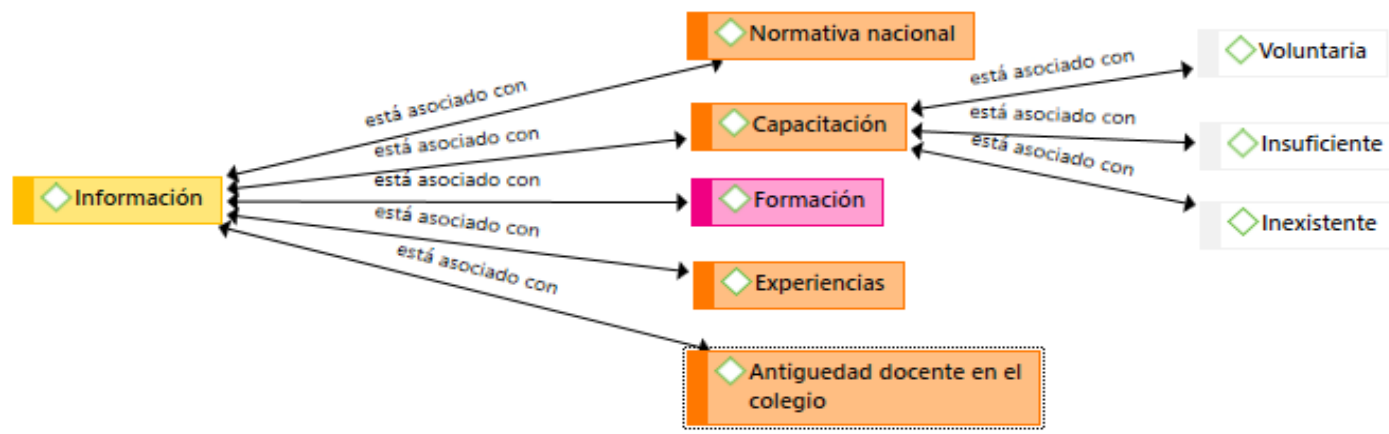

Fuente: ATLAS.ti 8.

52 Gloria Pérez Serrano y Santiago Nieto Martín, "La investigación-acción en la educación formal y no formal”, Enseñanza \& Teaching vol. 10-11 (1992): 1-22. 
El Diccionario de la lengua española define la palabra información, en su quinta acepción, como "comunicación o adquisición de conocimientos que permiten ampliar o precisar los que se poseen sobre una materia determinada"53. También es posible afirmar que la información está compuesta por conocimiento propenso a ser comunicado. En esta categoría se compendía la información poseída por los participantes respecto a la educación inclusiva y sus procesos, al principio, durante la revisión documental y al final de la investigación. En el gráfico 3 se ilustran las subcategorías emergentes durante el análisis del discurso inicial comprendido en esta categoría.

Las cinco subcategorías corresponden a las fuentes de la información que poseían los participantes con respecto a la educación inclusiva. Dichas fuentes son: la normativa nacional, la antigüedad docente en el colegio, capacitación, formación y experiencias. Con relación a la sub-categoría normativa nacional, los participantes mostraron una actitud favorable $\mathrm{y}$, al mismo tiempo, un desconocimiento marcado acerca de las directrices generales de la normativa, y se puede inferir que esto se debe a que el Plan de Implementación Progresivo (PIP), proyectado para el departamento de Santander, no se encuentra publicado a la fecha, por lo que no ha sido socializado con la comunidad, lo cual puede producir barreras que responden a la desinformación del profesorado, generando dificultad para la adecuada atención a la diversidad ${ }^{54}$.

La subcategoría de capacitación se relaciona con la de normativa nacional puesto que, en las partes del discurso inicial donde ambas se mencionan, se hace referencia a la responsabilidad del ente territorial frente a la capacitación docente en la implementación de normativas vigentes. A partir de lo evidenciado en esta subcategoría se puede deducir que las estrategias o formas de capacitación implementadas por el ente territorial a las instituciones educativas públicas tienen un bajo impacto en el trabajo docente, según lo referido por los participantes, y esto puede influir negativamente en la creación e implementación de políticas inclusivas, puesto que no sensibiliza ni capacita a la totalidad del cuerpo institucional atendiendo al contexto, dificultando así la apropiación de los procedimientos necesarios y la reconceptualización del papel de la escuela ${ }^{55}$ 565758

La formación profesional de los colaboradores también cobró relevancia como fuente de información; únicamente un docente reportó haber sido parte de la especialización en necesidades educativas especiales, en este caso ofrecida

53 Real Academia Española, Diccionario de la lengua española (Madrid: Real Academia Española, 23. ${ }^{a}$ ed.), https://dle.rae.es/información (9 de abril, 2020).

54 Miguel López Melero, "Barreras que impiden la escuela inclusiva y algunas estrategias para construir una escuela sin exclusiones", Innovación Educativa, n. ${ }^{\circ} 21$ (2011): 37-54.

55 Beltrán, Martínez y Torrado, "Creación de una comunidad de aprendizaje".

56 Booth y Ainscow, Index for inclusion.

57 Jorge Correa Alzate, Margarita Bedoya Sierra y Gloria Agudelo Alzate, "Formación de docentes participantes en el programa de educación inclusiva con calidad en Colombia", Revista Latinoamericana de Educación Inclusiva, vol. 9, n. ${ }^{\circ} 1$ (2015): 43-61.

58 Gary Thomas y Andrew Loxley, Deconstructing Special Education and Constructing Inclusion (Buckingham: Open University Press, 2001), 196. 
por el operador del proyecto en el año $2016^{59}$, y al existir solo un docente que acudiera a procesos de postgrado en torno a la inclusión, se puede inferir que ningún docente del plantel había recibido formación específica al respecto desde el pregrado o desde algún proceso de formación continuada, lo que según San Martín y otros ${ }^{60}$, dificulta la labor docente y el desarrollo de prácticas efectivas, pues los autores afirman que, para que la formación tenga mayor impacto en las prácticas inclusivas institucionales, es necesario que esta se obtenga desde los niveles de pregrado.

Las experiencias docentes que se asociaron con mayor sensibilidad hacia los procesos de educación inclusiva hacían referencia a eventos familiares que les ponían en contacto con situaciones en que sus hijos requerían apoyos educativos específicos, a partir de lo cual se puede inferir que la discapacidad promovía la necesidad de interacción constante entre el sistema familiar y el sistema escolar, lo cual concuerda con los planteamientos de Beltrán, Martínez y Torrado ${ }^{61}$, colocando al docente en el rol de padre de familia. Igualmente, los docentes que reportan experiencias exitosas reconocen la relación del éxito con la implementación de estrategias que aumenten las oportunidades de cooperación en el aula. Esto concuerda con la existencia de escenarios sociales desfavorables cuando es mencionada en la literatura como situaciones que también requieren de un enfoque educativo inclusivo, puesto que la atención que se brinda a partir del mismo no debe estar limitada a condiciones de discapacidad, sino que debe abarcar el amplio abanico de condiciones desfavorables que presenta el contexto colombiano en la actualidad 626364656667 , de donde es posible colegir que si los docentes están en la capacidad de reconocer estas situaciones y atenderlas desde un enfoque inclusivo, esto puede favorecer los cambios que el acompañamiento pretende introducir, ya que existe la sensibilización necesaria.

La antigüedad docente en el colegio también supuso una fuente de información y está directamente relacionada con las experiencias vividas en la institución educativa. Booth y Ainscow ${ }^{68}$, Granada, Pomés, Sanhueza ${ }^{69}$, y Ramón ${ }^{70}$

59 Mitra, "The capability approach".

60 Constanza San Martín, Cristóbal Villalobos, Carla Muñoz e Ignacio Wyman, "Formación inicial docente para la educación inclusiva. Análisis de tres programas chilenos de pedagogía en educación básica que incorporan la perspectiva de la educación inclusiva”, Calidad en la educación, n. ${ }^{\circ} 46$ (2017): 20-52.

61 Beltrán, Martínez y Torrado, "Creación de una comunidad de aprendizaje”.

62 CEPAL, La Agenda, 2030.

63 Simón y Echeita, "Educación inclusiva: ¿de qué?

64 Porter y Towell, Promoviendo la educación inclusiva.

65 Herrera, Pinilla e Infante, "Conflicto educativo y cultura".

66 Miryam Carreño, “Teoría y práctica de una educación liberadora: el pensamiento pedagógico de Paulo Freire”, Cuestiones Pedagógicas $n .^{\circ} 20$ (2009): 195-214.

67 Marcos Santos Gómez, "La perspectiva de las víctimas en la pedagogía liberadora de Paulo Freire", Revista de Educación n. ${ }^{\circ} 354$ (2011): 323-340. DOI. 10.4438/1988-592X-RE-2011-354-002

68 Booth y Ainscow, Index for inclusion.

69 Maribel Granada Azcárraga, María Pilar Pomés Correa y Susan Sanhueza Henríquez, "Actitud de los profesores hacia la inclusiva educativa", Papeles de Trabajo n. ${ }^{\circ} 25$ (2013): 51-59.

70 Carlos José Ramón Flórez, "La historia de vida como base de la percepción docente acerca del concepto de inclusión educativa. Caso de estudio: Institución Educativa Oriente Miraflores del municipio de Bucaramanga" (tesis maestría en educación, Universidad 
ratifican que una actitud más favorable frente a la educación inclusiva no está garantizada por la cantidad de años de servicio que tenga un profesor, si bien la experiencia previa en atención a la diversidad baja los niveles de ansiedad que se experimenten en ocasiones posteriores, puesto que le permite al docente replicar y optimizar lo ya intentado, convirtiendo las experiencias pasadas en un factor que impacta positivamente en su actitud frente a prácticas inclusivas. Adicional a la seguridad que la experiencia trae consigo, se denota que ser docente de área y ser docente director de un grupo tiene distintas implicaciones. Los docentes que tienen un solo grupo a su cargo tienden a tener mayor incidencia en los procesos estudiantiles que aquellos docentes que solo tienen contacto con los grupos por algunas horas semanalmente. Así, los docentes con menos tiempo dentro del colegio, que adicionalmente están a cargo de un área específica, suelen reportar mayor dificultad para el seguimiento de casos puntuales y para promover el compromiso parental. Esto puede deberse a lo mencionado por Granada, Pomés y Sanhueza ${ }^{71}$, quienes puntualizan en que, para implementar acciones educativas efectivas se requiere de tiempos suficientes con un grupo determinado, por lo que el factor temporal influye directamente en la actitud docente frente a la inclusión.

Como se pudo observar, a partir del análisis del discurso en torno a la categoría emergente de información, el panorama anterior al proceso de acompañamiento indicaba que la mayoría de los docentes participantes no poseía formación previa respecto a educación inclusiva o atención a la diversidad, que tampoco había recibido procesos de capacitación efectivos acerca de la normativa o la forma más adecuada de implementarla, y que los docentes de área presentaban mayor dificultad para hacer seguimiento a casos puntuales por el corto tiempo que disponían con cada grupo de estudiantes. Sin embargo, se pudo percibir una actitud favorable hacia la inclusión educativa gracias a la existencia de experiencias exitosas individuales y a que todos ellos reconocían la educación como un derecho inalienable, estrechamente relacionado con la socialización.

Dentro de los efectos del acompañamiento, se evidencia que los participantes tienden con más frecuencia a analizar las experiencias personales o ajenas, con base en la información que se socializó con ellos durante el acompañamiento para guiar el proceso, lo cual permite que la subcategoría de acompañamiento únicamente emerja durante el análisis de las entrevistas finales, por lo que su aparición se atribuye al impacto obtenido en la fase de acompañamiento, en la cual se les brindó información detallada a todos los docentes y directivos respecto a la interpretación y aplicación de las directrices legales ofrecidas por el MEN; esto era necesario según la perspectiva de varios autores ${ }^{72} 73$, quienes afirman que la formación y capacitación en temas relacionados con la educa-

Autónoma de Bucaramanga, 2015), 166.

71 Granada, Pomés y Sanhueza, "Actitud de los profesores".

72 Cabrera, “¿Qué debe saber y saber hacer un profesor?”.

73 Beltrán, Martínez y Torrado, "Creación de una comunidad de aprendizaje".

74 Correa, Bedoya y Agudelo, "Formación de docentes". 
ción inclusiva no debe ser dirigida a solo una porción de los docentes, sino que debe estar disponible para toda la comunidad educativa. Es por esto que, al hacer partícipe a todos los docentes de las capacitaciones y de la revisión de los documentos institucionales, gestando oportunidades de reflexión, escucha y concertación acerca del proceso, se logró avanzar con mejores resultados. Con base en lo anterior, se puede inferir que cuando los docentes encuentran utilidad práctica en la información que se les ofrece, tienden más fácilmente a incluirla dentro de su lenguaje cotidiano, lo cual evidencia un avance significativo del proceso puesto que asumir actitudes de reflexión frente a experiencias, tanto profesionales como familiares, permite ofrecer ayuda a otros en situaciones similares.

Gráfico 4. Categoría emergente acciones, junto con las subcategorías y categorías constituyentes con base en las cuales se desarrolló el análisis de las entrevistas iniciales.

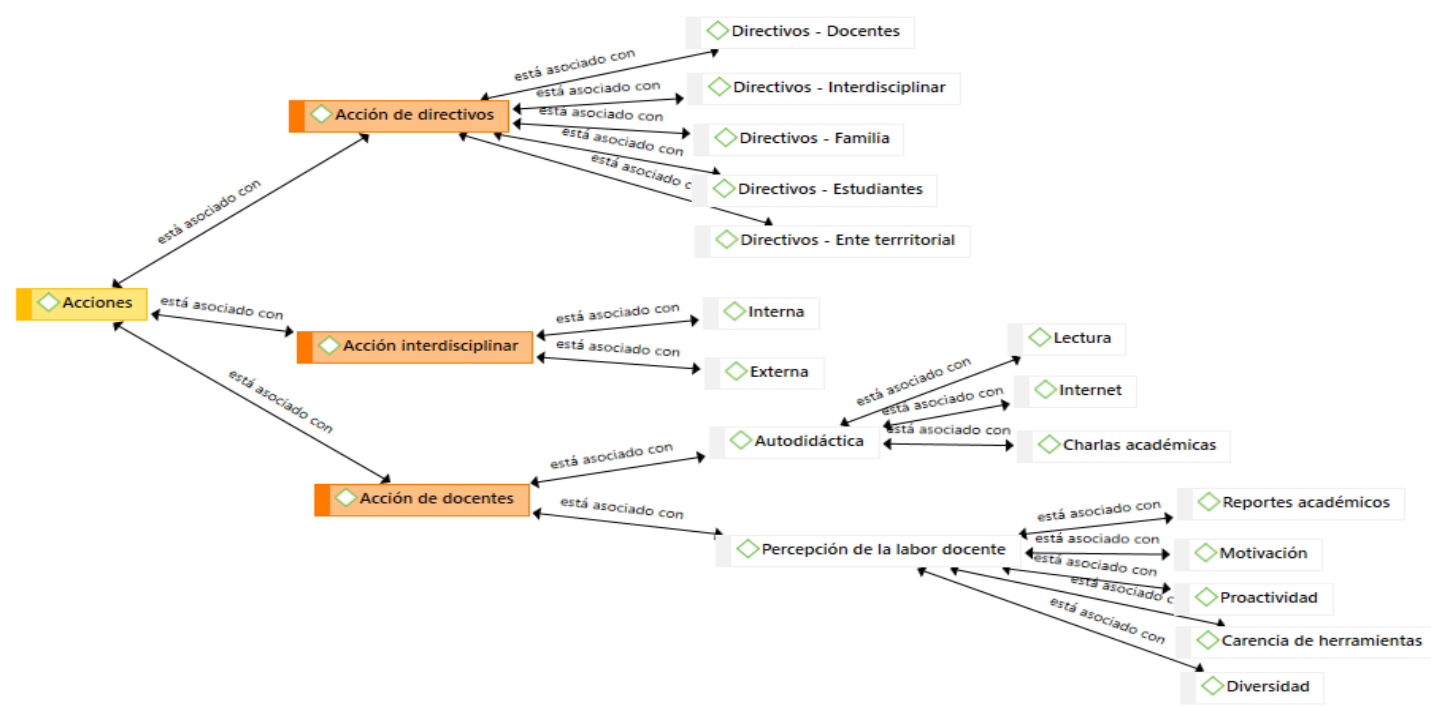

Fuente: elaboración propia basada en una imagen de ATLAS.ti 8.

Porter y Towel ${ }^{75}$ identifican a los estudiantes, los docentes, las familias, los profesionales de apoyo y los encargados de las políticas públicas como actores interrelacionados en los procesos educativos. La presente categoría acciones, compendía aquellos fragmentos del discurso de los participantes que narran actuaciones concretas de los actores en torno a los procesos de educación inclusiva. En el gráfico 4 se ilustran las subcategorías emergentes durante el análisis del discurso inicial comprendido en esta categoría.

En el discurso inicial de los participantes se identifican acciones concretas que evidencian el actuar de los directivos institucionales, del equipo interdisciplinar

75 Porter y Towell, Promoviendo la educación inclusiva. 
y de docentes, y cómo estas acciones se dirigen e impactan a los diferentes actores que conforman la comunidad escolar. Se permitió evidenciar en las entrevistas iniciales, que, aunque los participantes reportaron inconformidad con la acción interdisciplinaria tanto interna como externa al colegio, reconocen la labor directiva de liderazgo y puente de comunicación intrainstitucional como beneficiosa para el proceso, lo que a su vez impacta en la actitud docente. $\mathrm{Al}$ respecto, se identifica que los docentes reconocen frecuentemente el liderazgo y apoyo efectuados por parte de uno de los directivos del colegio, en el trabajo con estudiantes que requieran apoyos específicos. Se evidenció también que inicialmente, ante los procesos de inclusión, los docentes reportaban muchas dudas, las cuales respondían a carencia de herramientas y confusión frente a la emisión de reportes académicos, dificultades que son mitigadas por su autodidáctica y sensibilidad ante la atención a la diversidad. Posterior al proceso de acompañamiento se realizó la aplicación y análisis del discurso proveniente de las entrevistas finales, encontrándose que el discurso que hace referencia a la dimensión de las prácticas se complejiza, ya que aparecen nuevas percepciones de corresponsabilidad que impactan la dimensión cultural y apuntan a la modificación progresiva de las políticas institucionales. Por lo anterior se mantienen las subcategorías acción de directivos y acción de docentes, mientras surgen cuatro subcategorías nuevas: acción institucional, acción del sindicato, acciones propuestas y decremento de la actuación estatal.

Gráfico 5. Categoría emergente el estudiante, junto con las subcategorías y categorías constituyentes con base en las cuales se desarrolló el análisis de las entrevistas iniciales.

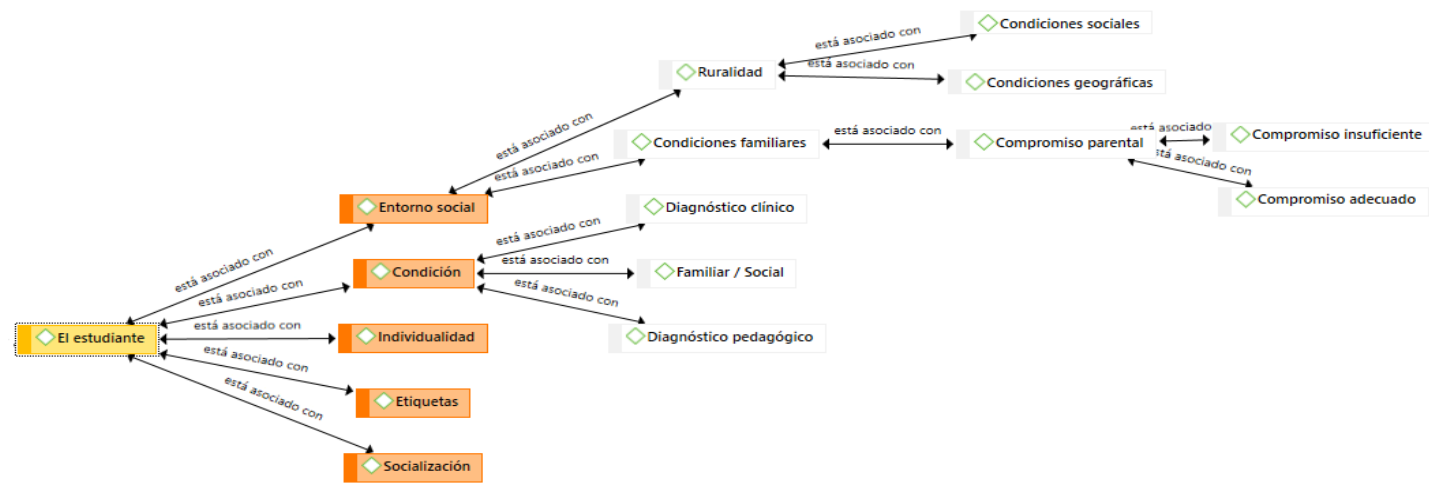

Fuente: elaboración propia basada en una imagen tomada de ATLAS.ti 8.

En la categoría emergente el estudiante se describen las características generales que suelen ser detectadas por los participantes en los estudiantes que requieren procesos de inclusión. El gráfico 5 ilustra las subcategorías emergentes del análisis del discurso inicial. Esta subcategoría se relaciona con la categoría emergente de información, en donde los docentes parten de reconocer la importancia de socializar para dirigir su labor. Las narrativas evidencian que, en medio de dichos procesos de socialización, se da en los estudiantes la construcción de 
las nociones de responsabilidad social y moralidad, lo cual corresponde a lo teorizado por $\mathrm{Kant}^{76} \mathrm{y}^{\mathrm{Beade}} \mathrm{e}^{77}$. En este proceso, según lo expuesto por Ausubel ${ }^{78}$, la influencia y dirección del docente resulta fundamental.

Como se pudo evidenciar durante las entrevistas iniciales, según los participantes la condición del estudiante está mediada por su entorno social, sus características individuales y sus procesos de socialización, encontrándose situaciones percibidas como más fácilmente manejables por los docentes de acuerdo con el nivel de apoyo y la información disponible en cada caso en particular. Posterior al proceso de acompañamiento se realizó la aplicación y análisis del discurso proveniente de las entrevistas finales, encontrándose que se mantienen las subcategorías de entorno social y socialización únicamente, a partir de lo cual se puede inferir que los participantes perciben estos dos factores como los más importantes en la educación infantil en aras de asegurar procesos de aprendizaje efectivos, restándole protagonismo a la deficiencia y a la carencia.

La categoría emergente barreras para la calidad educativa compendía todas las barreras para la calidad de los procesos educativos inclusivos que se detectaron en el sistema a partir del análisis de las entrevistas. Posterior al acompañamiento se evidenció que algunas de ellas fueron mitigadas mientras otras persisten en el sistema, pues requieren modificaciones adicionales que no pueden ser controladas desde los procesos investigativos. A continuación se ilustran en el gráfico 6 todas las barreras emergentes tanto en el discurso inicial como final.

Gráfico 6. Categoría emergente barreras para la calidad educativa junto con las subcategorías con base en las cuales se desarrolló el análisis de las entrevistas iniciales.

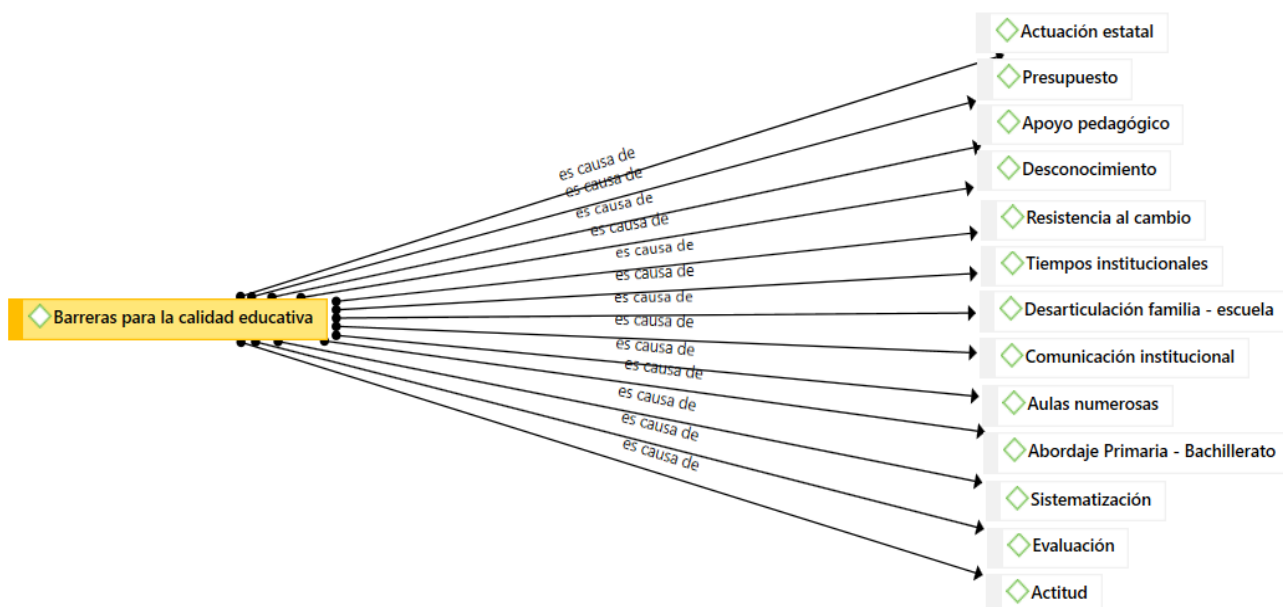

Fuente: elaboración propia basada en una imagen de ATLAS.ti 8.

76 Emanuel Kant, Tratado de pedagogía (Santiago de Chile: Universidad de Arte y Ciencias Sociales, 1981), 38.

77 Ileana Beade, "En torno a la idea de educación. Una mirada desde la reflexión pedagógica kantiana", Signos filosóficos vol. 13, n. ${ }^{\circ} 25$ (2011): 101-120.

78 Walter Arias Gallegos y Adriana Oblitas Huerta, "Aprendizaje por descubrimiento vs. aprendizaje significativo: un experimento en el curso de historia de la psicología”, Boletín Academia Paulista de Psicología, vol. 34, n. ${ }^{\circ} 87$ (2014): 455-471. 
Al hablar de la actuación estatal como una barrera detectada dentro de la institución, se encuentra que los docentes han percibido poco acompañamiento por parte del ente estatal, a pesar de requerirlo con frecuencia y de tener claras intenciones de aprovecharlo. En las entrevistas finales, el $9 \%$ de los participantes refiere en su discurso reconocer las acciones que ha realizado la Secretaría de Educación Departamental (SED) en cuanto a capacitaciones. Sin embargo, se evidencia que el proceso de capacitación es mínimo, ya que, de toda la planta docente del colegio, solo una docente cuenta con formación en procesos inclusivos y es considerada un apoyo importante para el colegio en ese tema. En el discurso final de los participantes se evidencia que esta barrera no ha sido mitigada debido a que la actuación del ente estatal es aún intermitente, insertando cambios aislados en el sistema, sin continuidad, lo cual limita o anula su impacto.

Como se ha mencionado en la descripción de los hallazgos de categorías emergentes y subcategorías anteriores, la percepción de la labor docente expone cómo esto afecta su motivación y por tanto se constituye en una barrera. La categoría constituyente presupuesto aún aparece en las entrevistas finales, motivo por el cual se considera una categoría persistente, y se infiere que lo expresado por Pulido ${ }^{79}$ es coherente con lo mencionado por los docentes.

En el contexto institucional, el apoyo pedagógico que reciben los docentes supone una barrera debido a que estos reportan en su discurso que el apoyo que reciben de la institución no es suficiente para atender todos los casos. Adicionalmente, también reportan carencia de apoyos interdisciplinarios fundamentales para articular procesos ${ }^{80}$. Esta subcategoría se evidencia en el análisis del discurso de las entrevistas finales, motivo por el cual se considera como una barrera persistente y en la cual el colegio tiene poca decisión ya que los apoyos son designados por la SED.

Se encontró que $81 \%$ de los participantes afirmaron inicialmente no conocer que eran los PIAR, lo cual también está relacionado con la subcategoría normativa nacional, y a su vez interfiere con la transmisión de información en cascada que debe desarrollar el ente territorial, según lo establecen Arenas y Margalef ${ }^{81}$. Sin embargo, dentro del análisis del discurso realizado a las entrevistas finales, se tiene que la barrera desconocimiento fue mitigada, encontrando que un $81 \%$ de los casos participantes expresan haber aclarado dudas en la implementación del PIAR, al realizar esta claridad se despejaron dudas sobre el trabajo y el desarrollo en la construcción de los planes de aula inclusivos, así como en la adaptación y empleo de la documentación que permite sistematizar los ajustes razonables de acuerdo con los procesos institucionales, proporcionando al colegio una minimización en la tensión que refirieron en las entrevistas iniciales, y se infiere que esto tiene relación con lo que afirman San Martín y otros ${ }^{82}$ en el sentido de que

\footnotetext{
79 Orlando Pulido Chaves, "La Federación Colombiana de Educadores (FECODE) y la lucha por el derecho a la educación. El Estatuto Docente", Ensayos \& Investigaciones del Laboratorio de Políticas Públicas n. 31 (2007): 1-58.

80 MEN, Decreto n. ${ }^{\circ} 1421$ de 2017.

81 Leonor Margalef García y Andoni Arenas Martija, “¿Qué entendemos por innovación educativa? A propósito del desarrollo curricular", Perspectiva Educacional, Formación de Profesores n. ${ }^{\circ} 47$ (2006): 13-31.

82 San Martín, Villalobos, Muñoz y Wyman, "Formación inicial docente para la educación inclusiva".
} 
la falta de capacitación, sumada al desconocimiento de prácticas pedagógicas actualizadas, limita la calidad educativa.

Se puede ver que, para asegurar una correcta actualización docente, es necesario trabajar jornadas de sensibilización en donde el docente sea presentado como agente protagónico, planificador, ejecutor y evaluador, para así minimizar la resistencia al cambio, y se maticen las percepciones que prevalecen en cuanto a la enseñanza tradicional, ya que al promover nuevos espacios para la actualización de sus prácticas se genera mayor seguridad y certeza de la labor pedagógica que contribuya a la formación de seres sociales funcionales ${ }^{83} 84$.

Se evidenció en las narrativas iniciales que existía una dificultad evidente respecto a contar con tiempos institucionales. Esto debido a que, al no contar con espacios asignados para capacitación, se desarrollan dentro de la jornada escolar, congestionando las actividades planeadas para las clases de los docentes. Se infiere con esto, y de acuerdo con lo expuesto por Porter y Towell ${ }^{85}$, que el no contar con tiempos institucionales impide el desarrollo de prácticas efectivas en torno a la inclusión.

Como se ha mencionado, otro de los factores que se reflejan como barreras para la educación es la participación de la familia. Dentro del análisis del discurso efectuado a las entrevistas finales se encontró que los participantes refieren haber llevado a cabo acciones con los padres de familia en pro de mejorar los procesos inclusivos educativos de los estudiantes. Lo anterior refleja que el acompañamiento realizado a la institución educativa favorece el proceder que presentan los docentes para con los padres de familia, así como a mantener comunicación con ellos de tal forma que puedan avanzar en la articulación y promoción de espacios y apoyos que contribuyen a la permanencia de los niños en el sector educativo.

El $27 \%$ de los participantes refiere en el discurso de las entrevistas finales una mejoría en la comunicación institucional, ya que perciben que están más unidos y que la afinidad entre compañeros les permite compartir y ayudarse entre ellos. De esta forma demuestran que establecer un acompañamiento técnico-pedagógico en el que se escuche y reflexione con la comunidad, permite mejorar el acople de los procesos, como lo expresan Arnaut ${ }^{86}$, y Calderón y Barraza ${ }^{87}$.

La subcategoría de articulación institucional obtenida por las entrevistas emerge solo en la entrevista final, demostrando en un $9 \%$ que el acompañamiento técnico-pedagógico favorece a la armonización de las actividades institucionales, minimizando las tensiones sobre la idea de sobrecarga que pueden tener los docentes ante la incorporación de nuevas acciones en su práctica.

83 Beltrán, Martínez y Torrado, "Creación de una comunidad de aprendizaje".

84 Correa, Bedoya y Agudelo, "Formación de docentes".

85 Porter y Towell, Promoviendo la educación inclusiva.

86 Alberto Arnaut Salgado, "La función de apoyo técnico - pedagógico: su relación con la supervisión y la formación continua", en La asesoría a las escuelas. Reflexiones para la mejora educativa y la formación continua de los maestros, ed. Secretaría de Educación Pública de México (México D.F.: Constantine Editores, 2006), 132.

87 Víctor Manuel Calderón Arambula y Arturo Barraza Macías, El acompañamiento del asesor técnico pedagógico y su implicación en la escuela secundaria técnica (México: Red Durango de Investigadores Educativos, 2015), 181. 
Debido a que la dinámica de atención a la primaria y al bachillerato presentan diferencias sustanciales en cuanto a personal docente y rotación del estudiantado, esto explica la creencia que reporta el discurso de los participantes, la cual afirma que en bachillerato no existen estudiantes con discapacidades o situaciones que requieran apoyos, debido a que la vinculación docente se ve limitada por los espacios y los tiempos. Esta subcategoría, que solo se presentó en el análisis del discurso de las entrevistas iniciales, evidencia cómo la invisibilización de las problemáticas que requieren apoyos dificulta la formulación de estos.

Las aulas numerosas se presenta en el análisis del discurso de las entrevistas iniciales, en donde los docentes tienen "aulas con 24, 25 o 26 dependiendo del grupo de niños, y en algunos casos pueden ser más", mientras que en las entrevistas finales hacen alusión a que aún se encuentran las aulas numerosas, pero la institución tiene en cuenta aquellas aulas en las que hay niños con discapacidad y estudia la conjugación del grupo para aminorar el impacto del docente, $\mathrm{y}$ a pesar de que esto se realice, los alcances del colegio siguen siendo pocos si también deben cubrir lo exigido por cobertura educativa, razón por la cual se considera como una barrera persistente.

La categoría sistematización en las entrevistas finales se establece como minimizada ya que, dentro del discurso, los docentes refieren que las acciones realizadas tienen impacto en la población, que ellos como docentes también deben estar en continuo aprendizaje, que el aprendizaje es bidireccional, que el trabajo de valores promueve una mejor socialización y desempeño del niño en el aula, y que el trabajo se puede hacer sin alterar negativamente el proceso de saber y actuar del docente. Y se infiere que esto está relacionado con lo expresado por Correa, Bedoya y Agudelo ${ }^{88}$, en donde sistematizar los procesos y dejar evidencia de lo realizado aporta significativamente al mejoramiento de las prácticas institucionales.

Como se expresó en apartados anteriores, los docentes presentan dudas acerca de los procesos de evaluación pertinentes para aquellos estudiantes que requieran flexibilizaciones curriculares. Esta situación deja ver que antes del proceso de acompañamiento, la comunidad desconocía los principios del Diseño Universal para el Aprendizaje y la existencia de otro tipo de ajustes. En el análisis del discurso de las entrevistas finales, se encuentra que el $72 \%$ de los participantes mencionó alternativas varias para la evaluación de los estudiantes, donde generalmente las facilidades en la evaluación se encuentran asociadas a las estrategias que otros compañeros docentes ya habían usado exitosamente en sus aulas. Es así como en las entrevistas finales quedó de lado la idea de estandarizar el pénsum y la inquietud de si se requería o no un boletín especial para los estudiantes, y por esto se considera una barrera mitigada.

En las entrevistas finales, el $36 \%$ de los participantes refieren mayor optimismo al proyectar el desarrollo de sus clases, y dejan de lado la percepción de que trabajar con estudiantes diversos es una carga, una mayor responsabilidad, y que generan más trabajo. Así como también refieren que hay mayores formas para integrarlos, esto se relaciona con la percepción de reto que mencionan en

88 Correa, Bedoya y Agudelo, "Formación de docentes". 
la categoría de percepción de la labor docente y resistencia al cambio. Esta categoría es fundamental ya que se relaciona y nutre todas las demás categorías, pues cada una afecta la forma y la percepción que se tiene del proceso, si es valorado o no, si es satisfactorio para el docente o no, si se avanza con apoyo o no, influye en la categoría de actitud, como lo expresa Ramón ${ }^{89}$.

El error de interpretación surge en las entrevistas finales y se asocia con los errores de interpretación que aún se mantienen, entre estos el mantener algunas etiquetas como "el estudiante de inclusión" o "los niños de necesidades especiales", lo cual alimenta el mantener las etiquetas como una forma adquirida para identificar a los estudiantes.

En el gráfico 7 se exponen las categorías mitigadas y persistentes para el final del acompañamiento.

Gráfico 7. Categoría emergente barreras para la calidad educativa, junto con las subcategorías mitigadas y persistentes, y las constituyentes con base en las cuales se desarrolló el análisis de las entrevistas finales.

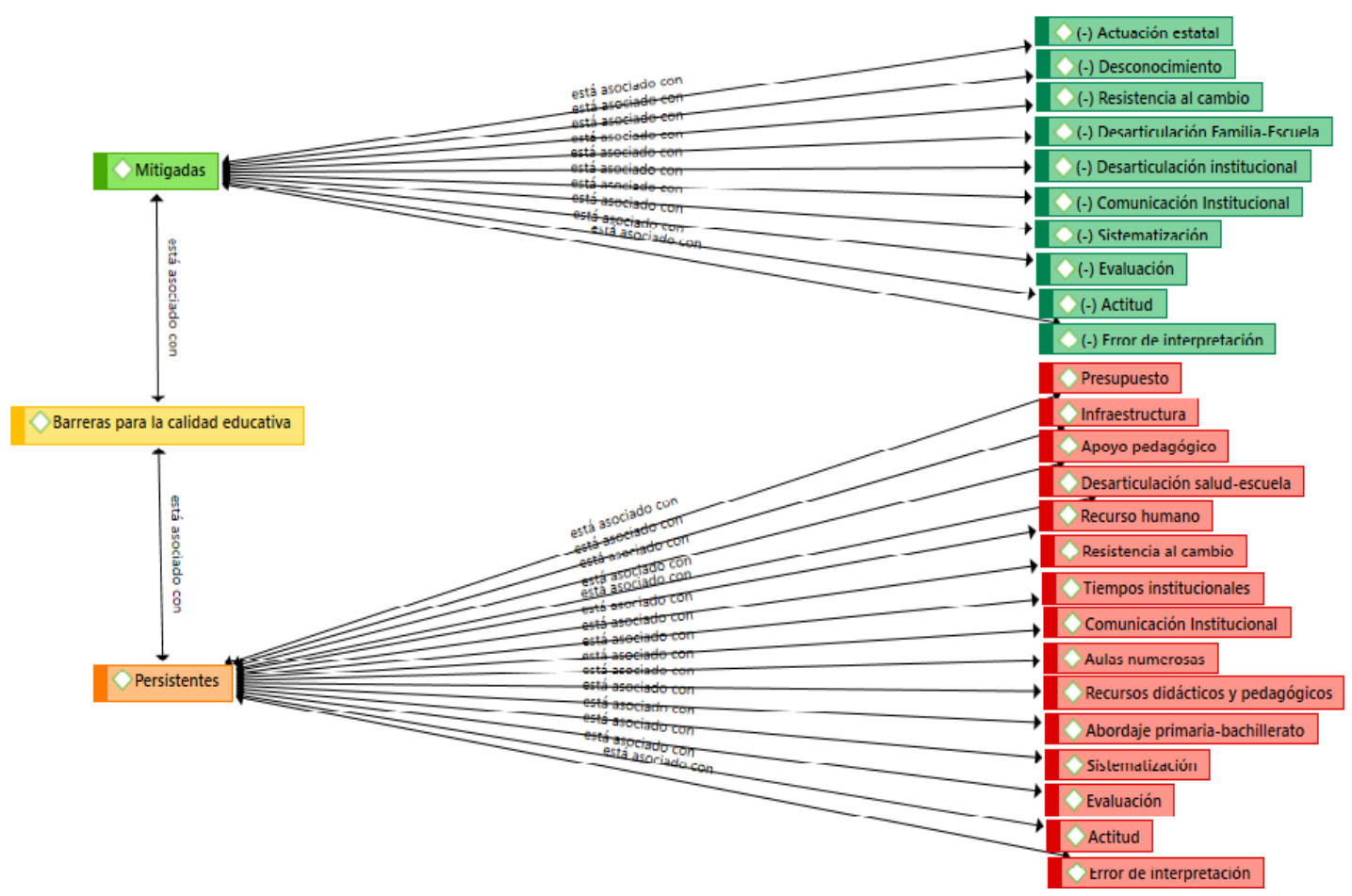

Fuente: elaboración propia basada en una imagen de ATLAS.ti 8.

89 Ramón, "La historia de vida como base de la percepción docente". 


\section{CONCLUSIONES}

Se identifican una serie de oportunidades y retos institucionales. A partir del impacto que muestran los resultados del proceso de investigación se puede concluir que, para formular un acompañamiento efectivo en la implementación de los lineamientos del Decreto 1421 de 2017, es fundamental atender a las características propias de cada institución, de los sistemas externos que la contienen y de los sistemas internos que la componen, lo cual constituye el reto más grande que enfrentan las instituciones educativas del país, pues según $\mathrm{O}^{\prime} \mathrm{Halon}^{90}$, la práctica inclusiva requiere ser desarrollada a través de procesos democráticos y contextualizados, en donde se propenda por el debate y la acción reflexiva entre los colaboradores. Cuando el discurso de la educación inclusiva en el contexto colombiano es entendido por una comunidad educativa como una oportunidad para la inclusión social, las prácticas inclusivas tienden a ser más efectivas que cuando se percibe el mismo discurso como una obligación impuesta y descontextualizada, ya que dentro de toda escuela se requieren procesos de escucha, participación y desarrollo aptos para todas las personas, independientemente de su rol, limitación o potencial académico, que a su vez favorezca la igualdad social y de oportunidades que propicia el modelo de derechos y que ubica a todos como iguales; mas no como la educación dirigida a personas con limitaciones físicas, sensoriales y cognitivas dentro de un aula regular, enfatizando la discapacidad. Esto se relaciona con la visión de los autores contemporáneos que conceptualizan las prácticas educativas inclusivas actuales y con el modelo de atención social de derechos, los cuales son producto de la corrección de prácticas exclusivas y segregatorias que los antecedieron ${ }^{91929394 .}$

Otras oportunidades detectadas en el sistema apuntan a la mejora institucional, ya que la comprensión del contexto permite actuaciones más eficaces y la generación de nuevas prácticas educativas acordes con las realidades sociales que se ven involucradas. Los modelos educativos usados en la institución, Escuela Nueva y Postprimaria, suponen otra oportunidad pues permiten mayor flexibilidad curricular y menor cantidad de estudiantes por aula, por lo que benefician los procesos de inclusión.

En cuanto a los retos, se identifica que las instituciones requieren la disposición y optimización de tiempos institucionales que permitan la planeación y el trabajo colaborativo docente, así como una mejor distribución de estudiantes por aula, pues cuando este número es muy alto disminuye el tiempo que el docente puede dedicar a conocer a cada estudiante. Otros retos tienen que ver con la disposición de líderes, la organización institucional y la formación de

\footnotetext{
90 O’Hanlon, Inclusión educacional.

91 Kathy Al Ju’beh, Disability Inclusive Development Toolkit (Berlín: CBM International, 2017), 166.

92 Gerardo Echeita Sarrionandia, "Inclusión y exclusión educativa. 'Voz y quebranto", REICE, Revista Iberoamericana sobre Calidad, Eficacia y Cambio en Educación, vol. 6, n. 2 (2008): 9-18.

93 Carlos Parra Dussan, "Educación inclusiva: Un modelo de educación para todos", Revista ISEES, n. ${ }^{\circ} 8$ (2010): 73-84.

94 Ángeles Parrilla Latas, "Acerca del origen y sentido de la educación inclusiva”, Revista de Educación n. ${ }^{\circ} 327$ (2002): 11-29.
} 
cada uno de ellos; estos factores deben ser debidamente tomados en cuenta por la institución para mitigar las fallas y dificultades del proceso de transición a una educación inclusiva. Unificar el sentido de la educación inclusiva con el cuerpo docente de cada institución es otro de los retos importantes identificados, frente a lo que se concluye que construir una visión común en el sistema escolar es necesario para poder impactar en la creación de culturas, políticas y prácticas inclusivas.

Por último, pudimos concluir que el acompañamiento técnico-pedagógico ante las reformas educativas, que permite la escucha y la reflexión de las prácticas institucionales de toda la comunidad educativa, genera mejor comprensión de los procesos educativos y de inclusión en los colaboradores, facilita la identificación de responsables, promueve la unión entre los actores del sistema y minimiza la resistencia al cambio. Proponer la incorporación de los cambios considerados en la normativa, de forma gradual y adaptados a la realidad institucional, genera un mejor afianzamiento de procesos y minimiza la percepción de una mayor carga laboral; este es el reto más importante que tienen las instituciones educativas $\mathrm{y}$, a su vez, el aporte más significativo que el presente proceso de investigación ofrece al campo de la educación, pues se comprueba que la sola existencia de la norma no garantiza, en la práctica, el acceso, la permanencia y la calidad educativa de todos los estudiantes, a menos que esté acompañada de procesos sistemáticos y contextualizados de implementación.

\section{REFERENCIAS}

Al Ju'beh, Kathy. Disability Inclusive Development Toolkit. Berlín: CBM International, 2017.

Araque Sierra, Heidy Tatiana y David Towell. "Fomentar la educación inclusiva para forjar una sociedad inclusiva". Bogotá: Centre for Inclusive Futures, 2011. https://www.javeriana.edu. co/documents/245769/2338340/FOMENTAR+EDUCAC+INCLUSIVA+FORJAR+SOCIEDAD+INCLUSIVA-DAVID-COTA.pdf/539338f5-7cc3-47b4-b814-57741a6413e2 (9/4/2020).

Archivo de Contratos, Secretaría de Educación (SED). Bucaramanga - Colombia. Gobernación de Santander.

Arias Gallegos, Walter y Adriana Oblitas Huerta. “Aprendizaje por descubrimiento vs. aprendizaje significativo: un experimento en el curso de historia de la psicología". Boletín Academia Paulista de Psicología, vol. 34, n. ${ }^{\circ} 87$ (2014): 455-471.

Arnaut Salgado, Alberto. “La función de apoyo técnico - pedagógico: su relación con la supervisión y la formación continua". En La asesoría a las escuelas. Reflexiones para la mejora educativa y la formación continua de los maestros, editado por la Secretaría de Educación Pública de México. México, D.F.: Constantine Editores, 2006.

Beade, Ileana. “En torno a la idea de educación. Una mirada desde la reflexión pedagógica kantiana". Signos filosóficos, vol. 13, n. 25 (2011): 101-120.

Beltrán Villamizar, Yolima Ivonne, Yexica Lizeth Martínez Fuentes, y Omar Elías Torrado Duarte. "Creación de una comunidad de aprendizaje: una experiencia de educación inclusiva en Colombia". Revista Encuentros, vol. 13, n. ${ }^{\circ}$ (2015): 57-72.

Booth, Tony y Mel Ainscow. Index for Inclusion: developing learning and participation in schools. Bristol: Centre for Studies on Inclusive Education, 2002.

Bustamante, Juan y Carolina Mejía,. "Acciones y herramientas de software para implementar entornos de inclusión educativa en Colombia". Teknos Revista Científica, vol. 17, n. 2 (2017): 38-45. 
Cabrera, Piedad. “¿Qué debe saber y saber hacer un profesor de estudiantes con talento académico?: Una propuesta de estándares de formación inicial en educación de talentos". Estudios pedagógicos, vol. 37, n. ${ }^{\circ} 2$ (2011): 43-59.

Calderón Arambula, Víctor Manuel y Arturo Barraza Macías. El acompañamiento del asesor técnico pedagógico y su implicación en la escuela secundaria técnica. México: Red Durango de Investigadores Educativos, 2015.

Carreño, Miryam. "Teoría y práctica de una educación liberadora: el pensamiento pedagógico de Paulo Freire". Cuestiones Pedagógicas vol. 20 (2009): 195-214.

Comisión Económica para América Latina y el Caribe (CEPAL), La Agenda 2030 y los objetivos del Desarrollo Sostenible, una oportunidad para América y el Caribe. Santiago de Chile: CEPAL, 2019. https://repositorio.cepal.org/bitstream/handle/11362/40155/24/S1801141_es.pdf (8/4/2020).

Correa Alzate, Jorge, Margarita Bedoya Sierra y Gloria Agudelo Alzate. "Formación de docentes participantes en el programa de educación inclusiva con calidad en Colombia". Revista Latinoamericana de Educación Inclusiva, vol. 9, n. ${ }^{\circ} 1$ (2015): 43-61.

Departamento Administrativo Nacional de Estadística (DANE). Informe Especial Censo General 2005 Colombia - Educación. Bogotá: DANE, 2005. https://www.dane.gov.co/files/censos/ boletines/bol_educacion.pdf (8/4/2020).

Departamento Administrativo Nacional de Estadística (DANE). Resultados Censo Nacional de Población y Vivienda 2018. Bogotá: DANE, 2018. https://www.dane.gov.co/files/censo2018/ informacion-tecnica/cnpv-2018-presentacion-3ra-entrega.pdf (9/4/2020).

Devís Devís, José; Jorge Fuentes Miguel y Andrew Sparkes. “Qué permanece oculto del currículum oculto? Las identidades de género y de la sexualidad en la educación física". Revista Iberoamericana de Educación, n. ${ }^{\circ} 39$ (2005): 73-90.

Echeita Sarrionandia, Gerardo. “Inclusión y exclusión educativa. 'Voz y quebranto'”. REICE, Revista Iberoamericana sobre Calidad, Eficacia y Cambio en Educación vol. 6, n. ${ }^{\circ} 2$ (2008): 9-18.

Echeita Sarrionandia, Gerardo. “Competencias esenciales en la formación inicial de un profesorado inclusivo. Un proyecto de la Agencia Europea para el Desarrollo de las Necesidades Educativas Especiales", Tendencias Pedagógicas, vol. 19 (2015): 8-24.

Echeita Sarrionandia, Gerardo. “Educación inclusiva: de los sueños a la práctica del aula”, Cuaderno de Educación n. 75 (2016): 1-9.

Médicis, M y Roicer Flórez Bolívar,. "Proceso de Integración Educativa: Accesibilidad, promoción y permanencia de personas sordas en el sistema educativo, en el nivel básica primaria en el sector público y privado en Bogotá, D.C.". Tesis de maestría en discapacidad e inclusión social, Universidad Nacional de Colombia, 2007.

Figueredo Vila, Elba Rosa, Ricardo Campuzano Peña y Clara María Rodríguez Vázquez. “Estrategia compensatoria dirigida a la estimulación del pensamiento en escolares con discapacidad intelectual leve", Revista Dilemas Contemporáneos: Educación, Política y Valores, n. ${ }^{\circ} 2$ (2019):1-21.

Granada Azcárraga, Maribel, María Pilar Pomés Correa y Susan Sanhueza Henríquez. “Actitud de los profesores hacia la inclusiva educativa". Papeles de Trabajo, n. ${ }^{\circ} 25$ (2013): 51-59.

Herrera, Martha Cecilia, Alexis Pinilla Díaz y Raúl Infante Acevedo. “Conflicto educativo y cultura política en Colombia". Nómadas, n. ${ }^{\circ} 15$ (2001): 40-49.

Hurtado Lozano, Leidys Tatiana y María Alejandra Agudelo Martínez. "Inclusión educativa de las personas con discapacidad en Colombia". Revista CES Movimiento y Salud, vol. 2, n. 1 (2014): 45-55.

Ibáñez, Ana María y Carlos Eduardo Vélez. Instrumentos de atención de la población desplazada en Colombia: Una distribución desigual de las responsabilidades municipales. Bogotá: Centro de Estudios sobre Desarrollo Económico, Universidad de los Andes, Facultad de Economía, 2003.

Kant, Emanuel. Tratado de pedagogía. Santiago de Chile: Universidad de Arte y Ciencias Sociales, 1981.

Lazcano Quintana, Idurre y Aurora Madariaga Ortuzar. “La experiencia de ocio en las personas jóvenes con discapacidad". Pedagogía Social. Revista interuniversitaria, n. ${ }^{\circ} 31$ (2018): 101-121.

López, Isabel Margarita y Gloria Elena Valenzuela. “Niños y adolescentes con necesidades educa- 
tivas especiales" Revista Médica Clínica Las Condes vol. 26, n. ${ }^{\circ}$ 1. (2015): 42-51.

López Melero, Miguel. "Barreras que impiden la escuela inclusiva y algunas estrategias para construir una escuela sin exclusiones". Innovación Educativa n. ${ }^{\circ} 21$ (2011): 37-54.

Margalef García, Leonor y Andoni Arenas Martija. “¿Qué entendemos por innovación educativa? A propósito del desarrollo curricular". Perspectiva Educacional, Formación de Profesores, n. ${ }^{\circ} 47$ (2006): 13-31.

Méndez Jiménez, Eudés Desiderio. “Estrategia de autoformación docente para mejorar el logro satisfactorio de aprendizajes en aula multigrado de la Institución Educativa n. ${ }^{\circ} 86627-$ Shocosh". Tesis de segunda especialización en gestión escolar con liderazgo pedagógico, Universidad San Ignacio de Loyola, 2018.

Ministerio de Educación Nacional (MEN). Orientaciones generales para la atención educativa de las poblaciones con discapacidad, en el marco del derecho a la educación. Bogotá: MEN, 2012. http://www.insor.gov.co/home/wp-content/uploads/filebase/orientaciones_poblacion_discapacidad_2012.pdf (9/4/2020).

Ministerio de Educación Nacional (MEN). Decreto n.ำ 1421 de 2017: por el cual se reglamenta en el marco de la educación inclusiva la atención educativa a la población con discapacidad. Bogotá: Presidencia de la República de Colombia, 2017. http://es.presidencia.gov.co/normativa/normativa/DECRETO\%201421\%20DEL\%2029\%20DE\%20AGOSTO\%20DE\%202017. pdf $(9 / 4 / 2020)$.

Mitra, Sophie. "The Capability Approach and Disability". Journal of Disability Policy Studies, vol. 16, n. ${ }^{\circ} 14$ (2006): 236-247.

Montes Miranda, Alexander Javier y Audin Aloiso Gamboa Suárez. “Miradas sobre la calidad de la educación básica en Iberoamérica: Visiones de España y Colombia". Revista Historia de la Educación Latinoamericana, vol. 20, n. ${ }^{\circ} 31$ (2018): 229-244.

O’Hanlon, Christine. Inclusión educacional como investigación-acción. Un discurso interpretativo. Bogotá: Editorial Magisterio, 2009.

Organización de las Naciones Unidas para la Educación, la Ciencia y la Cultura (UNESCO). "Garantizar el acceso a la educación para todos" (2005).

Parra Dussan, Carlos. "Educación inclusiva: Un modelo de educación para todos". Revista ISEES n. ${ }^{\circ} 8$ (2010): 73-84.

Parrilla Latas, Ángeles. "Acerca del origen y sentido de la educación inclusiva”. Revista de Educación, n. ${ }^{\circ} 327$ (2002): 11-29.

Pérez Serrano, Gloria y Santiago Nieto Martín. “La investigación-acción en la educación formal y no formal”. Enseñanza \& Teaching vol. 10-11 (1992): 177-198.

Porter, Gordon y David Towell. Promoviendo la educación inclusiva. Claves para el cambio transformacional en los sistemas de educación. Canadá: Inclusive Education Canada / Centre for Inclusive Futures, 2017. https://www.plenainclusion.org/sites/default/files/promoviendo_la_educacion_inclusiva.pdf (9/4/2020).

Pulido Chaves, Orlando. "La Federación Colombiana de Educadores (FECODE) y la lucha por el derecho a la educación. El Estatuto Docente". Ensayos \& Investigaciones del Laboratorio de Políticas Públicas, n. ${ }^{\circ} 31$ (2007): 1-58.

Programa Mundial de Alimentos (PMA). "Estudio de caso de las necesidades alimentarias de la población desplazada de Colombia". Bogotá: PMA, 2001. https://reliefweb.int/report/ colombia/estudio-de-caso-de-las-necesidades-alimentarias-de-la-poblaci\%C3\%B3n-desplazada-de $(9 / 4 / 2020)$.

Quintanilla Rubio, Leidy Vanessa. “Un camino hacia la educación inclusiva: análisis de normatividad, definiciones y retos futuros". Tesis de maestría en discapacidad e inclusión social, Universidad Nacional de Colombia, 2014.

Ramón Flórez, Carlos José. "La historia de vida como base de la percepción docente acerca del concepto de inclusión educativa. Caso de estudio: Institución Educativa Oriente Miraflores del municipio de Bucaramanga". Tesis de maestría en educación, Universidad Autónoma de Bucaramanga, 2015, 166.

Real Academia Española. Diccionario de la lengua española. Madrid: Real Academia Española, 2020. https://dle.rae.es/información (9/4/2020). 